\section{Recovery of sensory nerve fibres after surgical decompression in lumbar radiculopathy: use of quantitative sensory testing in the exploration of different populations of nerve fibres}

\author{
Ø P Nygaard, R Kloster, S I Mellgren
}

\begin{abstract}
Thirty nine patients with unilateral lumbar nerve root compression at one level were examined with quantitative sensory testing immediately before microdiscectomy and at six weeks, four months, and 12 months after surgery. Twenty one healthy volounteers were used as controls. The patients were classified as having a good or a poor result at the one year follow up. The improvement of function in small unmyelinated nerve fibres came within six weeks in the patients with a good result. By contrast the improvement of function in small myelinated fibres was not found before 12 months after surgery. The function in large myelinated fibres did not improve during the observation period. The difference in the time course of the recovery between large and small nerve fibres is assumed to reflect differing severity in the damage to the fibres before surgical decompression.

The preoperative warmth detection threshold reflecting the function in small unmyelinated $C$ fibres was significantly higher in the patients with a poor result and this may indicate that damage to $C$ fibres before surgery is a negative prognostic factor.
\end{abstract}

(F Neurol Neurosurg Psychiatry 1998;64:120-123)

Department of Neurology, University Hospital of Tromsø,

Norway

$\varnothing$ P Nygaard

S I Mellgren

Correspondence to: Dr Øystein P Nygaard, Department of

Neurosurgery, University

Hospital, 9038 Tromse

Norway. Telephone 47

77627091; Fax 47776 2705;

email:

oysteinn@fagmed.uit.no

Received 10 February 1997 and in final revised form 2 June 1997

Accepted 11 June 1997

The recovery of sensory function after surgical decompression in lumbar nerve root compression is not well known. Experimental studies of the effects of compression on the pig cauda equina have shown that the recovery of nerve function depends on the magnitude and duration of compression. ${ }^{12}$ These studies further show a significant difference between efferent and afferent conduction at the end of the recovery period. Thus the recovery of sensory function after surgical decompression may depend on various factors including duration of symptoms, nerve fibre size, and time after operation.

The purpose of this study was to investigate the recovery of function in different sensory nerve fibres after surgical decompression. The time course of the recovery may provide information on the pathophysiological mechanisms that are involved. ${ }^{3}$ Furthermore we wanted to determine if quantitative sensory testing (QST) could be used in the prediction of outcome after lumbar disc surgery.

\section{Method}

Thirty nine consecutive patients ( 14 women, 25 men) were examined immediately before microdiscectomy, and at six weeks, four months, and 12 months after surgery.

The mean age was 38 (SD 10) years (median 40 , range 20-59) and the mean duration of sciatica was 15 (SD 13) months.

The diagnostic criteria of nerve root compression were as follows: typical pain distribution, or motor symptoms, or both from compression of one lumbar nerve root (L5 or S1), pain distribution below the knee, positive Lasegue's test, unequivocal diagnosis of unilateral disc herniation at the corresponding level on lumbar CT or MRI, and confirmation of the diagnosis of lumbar nerve root compression due to disc herniation at the time of surgery. Exclusion criteria were as follows: (1) previous back surgery, percutaneous discectomy, or chymopapain injection (2), osseous stenosis or other disease of the lumbosacral spine, (3) diabetes, (4) other neurological disease, and (5) age over 60 years.

The QST was performed by the same invesThator and carried out in a silent room at $23^{\circ} \mathrm{C}$. Quantitative sensory thermotest was performed by the Marstock method with a thermostimulator operating according to the Peltier principle (Thermotest ${ }^{\circledR}$ type 1 , Somedic AB, Sweden). A thermode of $15 \times 25 \mathrm{~mm}$ was continuously applied to the dorsal side of one metatarsal (L5 dermatome), or the dorsal side of the 5th metatarsal (S1 dermatome). Baseline temperature was $30^{\circ}$ and slope $1 \%$ s. The temperature was continuously increased or decreased until the patient perceived a feel- 

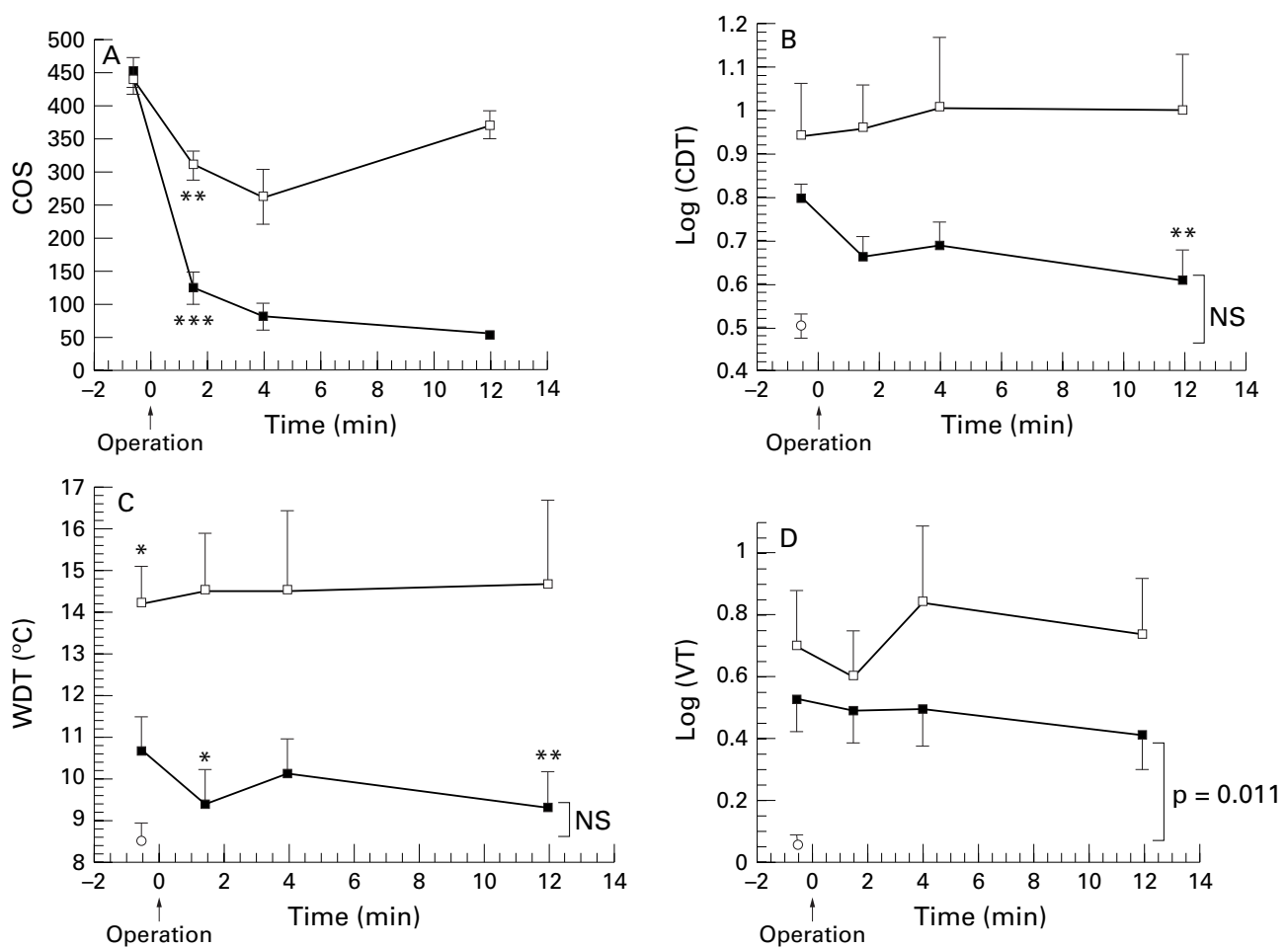

Clinical overall score (COS), (A); cold detection thresholds (CDT), (B); warm detection thresholds (WDT), (C); and vibration thresholds (VT), (D) in patients with a good (squares) and poor (open squares) result evaluated one year after the operation. Significant differences from preoperative values are indicated by $\star_{p}<0,05,{ }^{*} p<0,01$, and ${ }^{\star \star \star} p<0,001$. The $p$ values for the difference between patients with a good result at the one year follow up compared with controls (open circles) are given.

ing of cold or warmth. The patient then pushed a button, changing the current direction, and the thermode temperature returned to baseline. The limits of temperature were $5^{\circ} \mathrm{C}$ and $52^{\circ} \mathrm{C}$. Detection thresholds for cold (CDT) and warmth (WDT) were recorded. CDT and WDT were defined as the means of 10 adequate consecutive recordings.

Quantitative sensory vibrametry was performed using the Vibrameter ${ }^{\circledR}$ (Somedic, Sweden) on the dorsal side of the proximal first phalanx (L5 dermatome), or the dorsal side of the proximal fifth phalanx (S1 dermatome). The foot was resting on a soft surface. The vibration threshold (VT) was determined as the average of detection thresholds when the stimulus was successively increased. VT was determined four times at each site, and the means were calculated. When one of the four values differed more than $25 \%$ from one of the others, six values were determined and the highest and lowest value eliminated.

Twenty one healthy volounteers (seven women, $14 \mathrm{men}$ ) were used as controls. The mean age was 37 (SD 10) years (median 39, range 20-58).

To evaluate the clinical condition of the patients an overall examination as described by Haaland $e t a l^{4}$ was recorded at the same time intervals as the QST. The results of the examination were combined to give a clinical overall score (COS) for each patient at the different time intervals. The maximum COS was 1000 and represented the maximum of pain, clinical symptoms, and signs. At the one year follow up the patients were divided into two groups: good result $(\mathrm{COS}<250)$ and poor result (COS $>250)$. The examination at the 12 month follow up was performed by an independent observer.

Statistics was calculated using the univariate approach to analysis of variance for repeated measurements (RANOVA). Only when overall significance occurred were differences between different time points tested with contrast means comparisons. Association between pairs of continous variables was tested using simple regression analysis. Differences between pairs of groups were analysed using the $t$ test (two tailed). The recordings obtained for CDT and VT were positively skewed and therefore transferred to logarithmic values before statistical analysis. Data for age and duration of sciatica are given as mean(SD), otherwise mean (SEM) is used. $\mathrm{P}<0.05$ was considered significant.

\section{Results}

During the follow up one patient developed a deep venous thrombosis in the symptomatic leg, and one patient underwent a second disc surgery due to recurrent disc herniation. Both these patients were excluded from the study. The figure (A) shows the clinical overall score. In all of the patients the COS decreased significantly $(p<0.01)$ within the first six weeks after surgery, with a further decrease in the group of patients with a good result (30 patients).

THRESHOLDS OF COLD PERCEPTION (CDT) A significant decrease in CDT was not found before 12 months after surgical decompression in the patients with a good result $(\mathrm{p}=0.005$, figure (B)). At this time point there was no sig- 
nificant difference compared with the controls. The CDT in patients with a poor result did not change significantly.

THRESHOLDS OF WARM PERCEPTION (WDT)

The WDT showed the same pattern as CDT (figure (C)); however, the significant decrease in WDT in the patients with a good result came within the first six weeks after surgical decompression $(p=0.034)$. No further significant decrease was found beyond that time. At the 12 month follow up, no significant difference compared with controls was found. The WDT in the patients with a poor result did not change significantly during the postoperative observation period (figure $(\mathrm{C})$ ).

\section{THRESHOLDS OF VIBRATION (VT)}

The VT in patients with a good result decreased after surgical decompression; however, this decrease did not reach significance (figure (D)). There was a significant difference between the recordings at the 12 month follow up and controls $(\mathrm{p}=0.011)$. The VT in patients with a poor result did not change significantly after the operation (figure (D))

The preoperative thresholds for CDT, WDT, and VT were higher in the patients that were classified as having had a poor result than in the patients with a good result. This difference was, however, significant only for WDT (14.2 $(1.0)^{\circ} \mathrm{C}$ ข $10.7(0.8)^{\circ} \mathrm{C} \quad(\mathrm{p}=0.001)$. Simple regression analysis showed an association between the preoperative WDT and the COS at the 12 month follow up $\left(R^{2}=0.13, \mathrm{p}=0.031\right)$.

\section{Discussion}

This study demonstrates that the function of small afferent nerve fibres improved within one year after surgery. Warm detection thresholds improved within six weeks. The WDT reflects the function of small unmyelinated fibres (C fibres), ${ }^{56}$ and the time course of the recovery is compatible with the pathophysiological mechanisms involved being local metabolic conduction block due to local ischaemia or intraneural oedema. ${ }^{3}$ The CDT improved within 12 months after the operation. This reflects the function of small myelinated fibres (A $\delta$ fibres), ${ }^{56}$ and the time course of the recovery may imply that the pathophysiological mechanisms involved are local metabolic conduction block, damage to myelin, and probably some axonal involvement. ${ }^{3}$ Vibratory thresholds (VT) express the function of large myelinated sensory fibres $^{56}$ and the time course of the recovery indicates that the pathophysiological mechanism involved may be axonal damage as no significant improvement in the thresholds was found one year after surgical decompression. ${ }^{3}$

The different time course in the recovery of large and small nerve fibres reflects differences in the severity of damage to the fibres, the large fibres being more damaged than the small fibres before the operation. Our results are in accordance with previous studies on peripheral nerves indicating that large nerve fibres are more damaged than small myelinated fibres during compression. ${ }^{3-9}$
Several authors have investigated the effects of acute compression of lumbar nerve roots in the porcine cauda equina. Olmarker et $a l^{1011}$ found that the intrinsic vasculature of the nerve roots in the cauda equina was very sensitive to compression. Hyperaemia during the first postischaemic minutes suggested a nutritional deficit during the compression. With more prolonged compression an intraneural oedema formation was seen. In an experimental study Kobayashi et $a l^{12}$ have shown disruption of the blood-nerve barrier and intraradicular oedema in dogs subjected to acute compression of a lumbar nerve root.

Focal demyelination has been shown in experimental compression models of peripheral nerves, ${ }^{13}$ lumbar nerve roots, ${ }^{14}$ and in cadaveric studies of lumbar and cervical nerve roots. ${ }^{15}{ }^{16}$ Yoshizawa et $a l^{17}$ studied the effect of chronic compression of lumbar nerve roots in a dog model. After three months of compression a fallout in the large myelinated fibre population and increase of thinly myelinated fibres were seen in and around the peripheral part of the nerve root. Evidence of Wallerian degeneration was also seen.

The thresholds of quantitative sensory testing essentially remained unchanged after the operation in the group of patients with a poor result. This indicates that the function in both large and small nerve fibres was still altered. Continous compression of the nerve fibres may be the cause; however, mechanisms other than mechanical compression may be involved.

The preoperative thresholds for WDT was significantly higher in the group of patients with a poor result. The preoperative WDT was furthermore associated with the postoperative COS at the one year follow up in the whole population studied. As WDT reflects the function in small unmyelinated $\mathrm{C}$ fibres, this may indicate that damage to $\mathrm{C}$ fibres before the operation is a negative prognostic factor.

This work was supported by the University of Troms $ø$. We thank John Winther for technical assistance and Dr Mitch Weinstein for help with the manuscript.

1 Pedowitz RA, Garfin SR, Massie JB, et al. Effects of magnitude and duration of compression on spinal nerve root conduction. Spine 1992;17:194-9.

2 Rydevik BL, Pedowitz RA, Hargens AR, Swenson MR, Myers RR, Garfin SR. Effects of acute graded compression on spinal nerve root function and structure. Spine 1991;16: 487-93.

3 Lundborg G, Dahlin LB. The pathophysiology of nerve compression. Hand Clin 1992;8:215-27.

4 Haaland AK, Graver V, Ljungren AE, et al. Fibrinolytic activity as a predictor of the outcome of prolapsed intervertebral lumbar disc surgery with reference to background variables: results of a prospective cohort study. Spine 1992; 17:1024-7.

5 Gruener G, Dyck PJ. Quantitative sensory testing: Gruener G, Dyck PJ. Quantitative sensory testing:
methodology, applications and future directions. $\mathcal{F}$ Clin methodology, applications and

6 Light AR, Perl ER. Peripheral sensory systems. In: Dyck PJ, Thomas PK, eds. Peripheral neuropathy. Philadelphia: WB Saunders, 1993:149-63.

7 Dahlin LB, Shyu BC, Danielsen N, Andersson SA. Effects of nerve compression or ischemia on conduction properties of myelinated and non-myelinated nerve fibers. An experimental study in the rabbit common peroneal nerve. Acta Physiol Scand 1989;136:97-105.

8 Fowler TJ, Ochoa J. Unmyelinated fibers in normal and compressed peripheral nerves of the baboon: a quantitative electron microscopic study. Neuropathol Appl Neurobiol 1975;1:247-65.

9 Nygaard ØР, Trumpy JH, Mellgren SI. Recovery of sensory function after surgical decompression in carpal tunnel sunfunction after surgical decompression in carp.

10 Olmarker K, Rydevik B, Holm S. Edema formation in spinal nerve roots induced by experimental graded compression. Spine 1989;14:569-73. 
11 Olmarker K, Rydevik B, Holm S, Bagge U. Effects of experimental graded compression on blood flow in spinal nerve roots. A vital microscopic study on the porcine cauda equina. F Orthop Res 1989;7:817-23.

12 Kobayashi S, Yoshizawa H, Hachiya Y, Ukai T, Morita T. Vasogenic edema induced by compression injury to the spinal nerve root. Spine 1993;18:1410-24.

13 Powell HC, Myers RR. Pathology of experimental nerve compression. Lab Invest 1986;55:91-100.
14 Garfin SR, Cohen MS, Massie JB, et al. Nerve-roots of the cauda equina. F Bone foint Surg Am 1990;72:1185-92. Hoyland JA, Freemont AJ, Jayson IV. Intervertebral foramen venous obstruction. A cause of periradicular fibrosis? Spine venous obstruction.

16 Oishi Y, Ohnishi A, Suzuki K, Hojo T. Lower number and thinner myelin of large myelinated fibers in human cervical compression radiculopathy. F Neurosurg 1995;83:342-47.

17 Yoshizawa H, Kobayashi S, Morita T. Chronic nerve root compression. Spine 1995;20:397-407.

\section{Fournal of Neurology Neurosurgery and Psychiatry - http://www.jnnp.com}

Visitors to the world wide web can now access the fournal of Neurology Neurosurgery and Psychiatry either through the BMJ Publishing Group's home page (http://www.bmjpg.com) or directly by using its individual URL (http://www.jnnp.com). There they will find the following:

- Current contents list for the journal

- Contents lists of previous issues

- Members of the editorial board

- Subscribers' information

- Instructions for authors

- Details of reprint services.

A hotlink gives access to:

- BMJ Publishing Group home page

- British Medical Association web site

- Online books catalogue

- BMJ Publishing Group books.

The web site is at a preliminary stage and there are plans to develop it into a more sophisticated site. Suggestions from visitors about features they would like to see are welcomed. They can be left via the opening page of the BMJ Publishing Group site or, alternatively, via the journal page, through "about this site". 